\title{
Adolescent girls' perceptions of breastfeeding in two low-income periurban communities in South Africa
}

\section{Virginia Zweigenthal, Anna Strebel \& Jo Hunter-Adams}

To cite this article: Virginia Zweigenthal, Anna Strebel \& Jo Hunter-Adams (2019) Adolescent girls' perceptions of breastfeeding in two low-income periurban communities in South Africa, Health Care for Women International, 40:7-9, 995-1011, DOI: 10.1080/07399332.2018.1549043

To link to this article: https://doi.org/10.1080/07399332.2018.1549043

\section{曲 Published online: 17 Apr 2019.}

Submit your article to this journal 2

Џll Article views: 193

Q View related articles $\sqsubset$

View Crossmark data $₫$ 


\title{
Adolescent girls' perceptions of breastfeeding in two low-income periurban communities in South Africa
}

\author{
Virginia Zweigenthal $^{\mathrm{a}}$ (D), Anna Strebel ${ }^{\mathrm{b}}$, and Jo Hunter-Adams ${ }^{\mathrm{c}}$

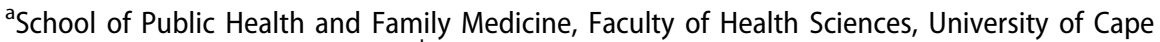

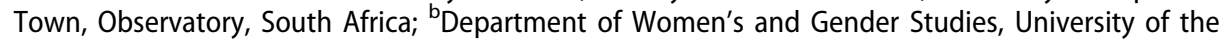 \\ Western Cape, Bellville, South Africa; ' ${ }^{C}$ ealth Economics Unit, School of Public Health and Family \\ Medicine, Faculty of Health Sciences, University of Cape Town, Observatory, South Africa
}

\begin{abstract}
In South Africa, exclusive breastfeeding rates are low, and rates of teenage pregnancy are high. Educational policy enables mothers' return to school, which conflicts with policy emphasizing exclusive breastfeeding. We elicited adolescent women's perceptions and experiences of infant feeding choices, and conducted six focus groups $(N=57)$ in two periurban settlements. Participants knew arguments in favor of and against breast and formula-feeding, but in practice, mixed feeding occurred early after birth. While completion of high school was emphasized, exclusive breastfeeding was viewed as impractical. Congruent education policies and infant feeding policies/guidelines must address the constraints and contexts of adolescent mothers.
\end{abstract}

\section{ARTICLE HISTORY}

Received 15 April 2018

Accepted 13 November 2018

In South Africa, until recently, marketing of infant formula was unregulated (Department of Health, 2012), and the widespread advertisement and availability of formula may have increased the use of and desire for formula-feeding, which contributed to the low exclusive breastfeeding rates observed (Doherty et al., 2012). Until 2013, following infant feeding guidelines, formula was dispensed routinely for HIV-infected women attending government health services (Department of Health, 2013), which additionally may have contributed to low breastfeeding rates. Currently, however, given that breastfeeding is recommended for infants of most HIV-infected women, exclusive breastfeeding until six months is encouraged and universally promoted in accordance with international guidelines. At the same time, rates of teenage pregnancy in SA are high, with $30 \%$ of teenage girls aged 13-19 reporting ever being pregnant (Jewkes, Morrell, \& Christofides, 2009). In 2012, 71 births per 1000 were born to women aged 15-19 (Statistics South Africa, 2012). Given that many pregnant adolescents drop 
out of school, with adverse consequences for themselves and their children, official policy seeks to facilitate young mothers' continued learning, and their return to school to complete secondary education (Panday, Makiwane, Ranchod, \& Letsoalo, 2009). As may be found in other settings, it is not apparent how health policy, which focuses on exclusive breastfeeding and the well-being of the baby, aligns with education policy, which focuses on the well-being of the mother. In this context, we explored the perceptions and implications of breastfeeding in relation to school attendance of adolescents with infants among adolescent school-aged women.

\section{Background}

The 'first 1000 days of life' - the time from conception to a child's second birthday - is widely recognized as a critical window of opportunity for the optimal development of children (Bhutta et al., 2013). This approach to child health acknowledges the pivotal role of mothers and the importance of their well-being. It considers that families, communities and structural factors impact on the health of infants. The 'First 1000 days' paradigm, by acknowledging the impact of factors outside the health sector on child health and optimal growth, highlights that interventions that promote the well-being of mothers will consequently promote child health. Therefore, it is important that infant feeding policy and educational policy that promotes the return of the adolescent mother to school are congruent rather than conflicting.

\section{Breastfeeding in South Africa}

Findings from qualitative studies among SA lactating mothers indicate very low rates of exclusive breastfeeding (Bland, Rollins, Coutsoudis, \& Coovadia, 2002; Nor et al., 2012; Sibeko et al., 2005). Mothers had poor understanding of the meaning of 'exclusive breastfeeding' (Nor et al., 2012), commonly used traditional herbal preparations in the first months of life (Sibeko et al., 2005), and introduced complementary foods early (Nor et al., 2012; Sibeko et al., 2005). In addition, many women believed that inadequate breast milk supply was common, and began supplementation early as a result (Nor et al., 2012) . One community-based study from two SA provinces, KwaZulu-Natal and the Western Cape, found that at 12 weeks postpartum, $20 \%$ of HIV-negative women had stopped all breastfeeding, and about a third of women had introduced other fluids within three days of birth (Doherty et al., 2012).

Health care workers play an important role in mothers' selection of infant feeding options. Historically, breastfeeding guidelines were not well 
understood by SA's clinicians, nursing staff and community health workers (CHWs). A study in rural Kwa-Zulu Natal found that $71 \%$ of doctors recommended water and 50\% recommended solids to breastfed infants under six months of age (Shah, Rollins, Bland, \& Group, 2005). Only 44\% of professional nurses knew that breastfeeding should be on demand, and $68 \%$ of CHWs thought that breastfeeding should be on a schedule. In addition, family members also pressured women to introduce complementary foods and fluids early (Doherty, Chopra, Nkonki, Jackson, \& Greiner, 2006).

In addition, breastfeeding norms have been shaped by the high prevalence of HIV in South Africa. Feeding guidelines for HIV positive women have shifted over time, and it is only recently that breastfeeding is more widely recommended for all HIV-uninfected and most HIV-infected women. However, exclusive breastfeeding involves much less risk of HIV transmission than mixed feeding (Coovadia et al., 2007), and so guidelines for HIV-positive women are tailored accordingly.

Currently, the policy focus on breastfeeding is motivated by health benefits to the infant, and is designed to create environments and knowledge that facilitate exclusive breastfeeding for six months, with few exceptions. While creating positive contexts for exclusive breastfeeding remains difficult, it is doubtful that current infant feeding policy is flexible enough to allow for the tailoring of recommendations to fit women's circumstances. Indeed, the narrative that breastfeeding is "not well understood" by community health workers, nurses and doctors, suggests that guidelines (previous or current) may be difficult to translate into lived experiences.

\section{Adolescent pregnancy in South Africa}

Around 30\% of teenage girls aged 13-19 have reported ever being pregnant (Jewkes et al., 2009). Rates of adolescent pregnancy in SA have declined slowly since 1996 (Panday et al., 2009). Nevertheless, historically adolescent pregnancy rates are high relative to overall fertility rates (Kaufman, Wet, \& Stadler, 2001).

While there is little current data on rates of school dropout in relation to pregnancy, in 1998 about 36\% of girls who dropped out of school did so because of pregnancy (Timæus \& Moultrie, 2015), despite relatively progressive policy on the part of the SA Education Department. While policy encourages "pregnant girls to remain in school and young mothers to return to school after giving birth," "implementation of these principles varies between provinces and from school to school." (Grant \& Hallman, 2008, p. 144). About one-third of those who become pregnant return to school, with the largest proportion returning if they are in their final school year (Grant \& Hallman, 2008). Key reports on teenage pregnancy highlight 
that those becoming pregnant as young teens (13-16) are less likely to return to school and perform poorly compared to those who become pregnant as older teens (17-19) (Bearinger, Sieving, Ferguson, \& Sharma, 2007).

Policy related to adolescent pregnancy is focused on long-term outcomes for adolescents, and so emphasizes school attendance, as completing schooling confers advantage for future employment, further tertiary education, and consequent socio-economic status. This creates a potential disjuncture, as continued school attendance inevitably makes exclusive breastfeeding challenging. The infant-feeding practices of adolescents depends on the roles of various supportive structures - the school, the health services and the family. In this article, we are interested in exploring this disjuncture.

\section{Adolescent breastfeeding}

While breastfeeding guidelines have become more consistent in SA in the past five years, with all women encouraged to breast-feed exclusively for six months as per WHO recommendations, attention to breastfeeding as part of adolescent sexual and reproductive health has been limited (Bearinger et al., 2007). There is, nevertheless, a significant global body of literature focused on breastfeeding among adolescents (Dykes, Moran, Burt, \& Edwards, 2003; Hannon, Willis, Bishop-Townsend, Martinez, \& Scrimshaw, 2000; Wambach \& Cohen, 2009; Woods, Chesser, \& Wipperman, 2013). However, the literature largely focuses on mechanisms to increase the rates and exclusivity of breastfeeding. For example, in one study of the Canadian Ojibwa community, school-based breastfeeding education modestly affected breastfeeding and bottle-feeding beliefs (Martens, 2001). A small study exploring telephone peer support found this increased exclusive breastfeeding duration from a median of 10 to 35 days, but had no impact on the length of breastfeeding overall (Meglio, McDermott, \& Klein, 2010).

Several studies have investigated the factors influencing adolescent mothers' ability to breast-feed. Nesbitt and colleagues highlight a distinction between "trying" to breast-feed versus "committing" to breast-feed prenatally (Nesbitt et al., 2012). An urban US adolescent mothers study, exploring the impact of the availability of social support, found that those exposed to breastfeeding role models were more likely to choose breastfeeding (Wambach \& Cohen, 2009). Mothers' comfort with breastfeeding was investigated in a study of African-American and Latina adolescent mothers' infant feeding decisions. Mothers described the challenges of breastfeeding in terms of pain, public exposure, unease with act of breastfeeding, breastfeeding myths (unhealthy to breast-feed if you're eating junk food), 
inconvenience, and return to school (Hannon et al., 2000). Lack of knowledge about the benefits of breastfeeding was highlighted in a study of young child nutrition in Bangladesh. Young mothers did not necessarily have more knowledge of the benefits of breastfeeding than other, even younger, nulliparous peers (Hackett, Mukta, Jalal, \& Sellen, 2015). Key knowledge gaps included misinterpretations of the meaning of 'exclusive breastfeeding'; confusion regarding appropriate timing of initiation and duration of breastfeeding; negative expectations regarding breast milk production; and confusion about appropriate complementary feeding practices in relation to the baby's health and intelligence (Hannon et al., 2000).

A growing interest in the role of grandmothers in breastfeeding is also reflected in the international literature. For example, in Brazil where teenage mothers reside with their mothers, it was important to update these grandmothers about breastfeeding practices, which in turn influenced breastfeeding practice of adolescent mothers (Bica \& Giugliani, 2014). In Thailand, grandmothers have been identified as key to promoting, protecting and supporting breastfeeding (Bootsri \& Taneepanichskul, 2017). In an urban Brazilian study, including adolescent mothers and grandmothers in counseling during the first four months of children's lives proved to be effective in increasing exclusive breastfeeding duration among adolescent mothers (de Oliveira, Giugliani, do Espírito Santo, \& Nunes, 2014).

As with the broader breastfeeding literature, the body of adolescentfocused breastfeeding literature reflects a focus on education, with the goal of facilitating breastfeeding and increasing rates of exclusive breastfeeding. Again, the underlying assumption is that breastfeeding should always lead to the best outcome for babies. Yet few studies are based in low-and-middle income countries, and these studies tend not to discuss contexts for school attendance after birth.

\section{Our contribution}

In this study, we wish to contribute to understanding South African adolescents' perceptions of breastfeeding, particularly in the context of educational policy advocating for continued school attendance. We wanted to explore the implications of study findings for policy that focuses on both the health of the baby as well as the health of mother.

\section{Methods}

Our research aim was to analyze collective perceptions and experiences of school age young women regarding breastfeeding in two low-income, periurban neighborhoods in Cape Town, South Africa. To achieve this, two 
field workers, fluent in the dominant languages of the two communities, conducted six focus group discussions $(N=6)$ with a total of 57 school age young women, aged 16-18, three in each of the two communities. We used snowball sampling through local community organizations and key informants to identify participants. Groups ranged from six to 15 participants, and sessions lasted, on average, $1 \mathrm{~h}$ and $15 \mathrm{~min}$. Groups included both participants who had themselves had babies and those who had not. While some participants volunteered information about previous pregnancies, we did not seek this information out, as it is potentially sensitive. The groups were conducted at the premises of local NGOs, in the language of choice of participants, namely Afrikaans, English, or Xhosa.

One of us has longstanding and ongoing research projects in these neighborhoods, and one other is linked to the provincial health department. Our longer-term goals were to learn from participants about the dominant narratives related to breastfeeding, and to connect our analysis of this narrative to policy.

We designed the interview guide to include questions about family, school, and peer reactions to teenage pregnancies, schooling for pregnant adolescents and new mothers, infant feeding choices for adolescent mothers, and feeding options in the light of HIV infection. Professional transcribers transcribed recordings verbatim, and when other languages were spoken, professional translators translated the texts into English. Two members of the research team checked the transcripts for quality.

All authors then read through transcripts, roughly following the methodology of thematic analysis (Boyatzis, 1998): The authors then met in person several times to discuss potential themes and created a summary document that conveyed an initial analysis of dominant narratives. This process was largely inductive - that is, we did not attempt to fit participants' discussion into predefined narratives, though focus group discussion questions did guide the resultant text somewhat. Our choice of what to include and exclude in the manuscript was guided in part by how these themes related to the South African and international literature around breastfeeding, and in part by what seemed most important to participants.

\section{Ethics}

We declare that the protocol complies with the Declaration of Helsinki (Fortaleza, Brazil 2013). This study was approved by the Human Research Ethics Committee (Ref: HREC 273/2017) of the University of Cape Town. Written informed consent included an outline of the purpose of the research, risks and benefits, and the opportunity to opt out before or during the interview. Participants received a gift card of R50 (US\$4) in 
appreciation for the time spent, and snacks and drinks were provided during sessions. Informed consent and permission to audio-record the sessions were obtained before the group discussions. Transcripts were blinded and both audio and written transcripts were kept securely in password protected electronic documents.

\section{Results}

In keeping with the focus of the study, respondents raised a variety of issues regarding their perceptions of infant feeding options and practices for adolescent mothers, including HIV and infant feeding, as well as considerations in returning to school after childbirth.

\section{Feeding options: breast vs. formula}

There was wide-ranging discussion among participants about their perceptions of infant feeding practices among young women in their communities. They identified the many positive arguments in favor of breastfeeding. These included beliefs that breastfeeding was natural and healthier than formulafeeding, and that it allowed for bonding between infant and mother:

I'd say breast milk is healthier because there's no artificial nutrients and preservatives in breast milk like there would be in formula milk.

I think breastfeeding is important because breastfeeding brings a closer bond.

There was generally consensus that breastfeeding should ideally occur exclusively for the first six months after the birth.

A variety of arguments against breastfeeding were also raised. There was a sentiment that some babies reject the breast, or that breastfeeding was very time-consuming:

Sometimes the baby does not want the breastmilk. For some reason the baby just stop $[\mathrm{s}]$ drinking the breastmilk. $[\mathrm{mm}]$ Then the mothers don't have a choice but to give them formula because the child can starve.

[It is] difficult to breast-feed, [it] is time consuming because you have to sit ... And then you don't get time to make food. Yoh!

In addition, there were perceptions that breastfeeding could result in several negative/uncomfortable experiences for the mother, in that they may get sore nipples, or the milk might leak. Moreover, breastfeeding could have a negative impact on the appearance of the mother's breasts:

When you, it's your first time in breastfeeding you experience pain in your nipples and your breast, and your breast[s] are heavy. As the baby is feeding on your breast it feels like you have sores 
If I breast-feed then my breast is going to be hanging or something like that so they choose to use the formula instead.

Turning to formula-feeding, participants indicated reasons for using formula instead of breastfeeding. These included formula feeding if the baby was not thriving and to enable the mother to return to school or work. Also, weaning meant that the mother had more freedom:

I fed mine porridge after two weeks because I noticed that he doesn't get full with breast milk and he was always crying. But when I tried feeding him porridge, just with a small amount of porridge, he ate it and he never gave me any troubles after that.

And also mothers they can't also always breast-feed because they must go to work. The formula comes handy. You take your child to crèche they are not going to wait for the mother... They're going to make the bottle and give it to the child. So the formula is easier.

[Bottle-feed] so that I can have my fun times.

Nevertheless, there was a strong concern about the high cost of formula, especially for women who did not receive financial support from their family or partner:

And maybe I am not working, I am depending on the child grant. So then it makes it hard to feed the children. Most of the time the child is not eating well enough.

Many young mothers adapted their infant feeding practices in a variety of different ways. These included diluting the formula, or introducing other beverages like tea. In addition, various solids were introduced, including mash, porridge, yoghurt, or in fact eating whatever the adults in the household were eating:

But then it was like vegetables, soft, soft vegetables that he could eat. And then later on when he got a bit older, then they put chicken and stuff in the food.

The best I tell, it's the mashed potatoes. Because like breastfeeding, breast milk is not making the baby full, so that is why they prefer formula and vegetables.

In practice, it seemed that mixed feeding was common, with many reporting that young women started their babies on some form of solids like diluted porridge almost from birth. This was often seen as being a matter of convenience, especially if the mother was returning to school or work:

I say, do both, breast-feed ... get the child used to both bottle-feeding and breastfeeding whilst they are young. So that when you are at home and can breastfeed you are able to and when you are at school you can also leave them with the bottle, because the child will already be used to it. So it's important to get them used to both while they are still young. 
Local clinics, NGOs, and hospitals were largely seen as supportive, teaching young women how to breast-feed, and not discharging them until they were successful. According to participants, medical staff also advised young mothers to breast-feed exclusively for the first 6 months, but also reportedly recommended giving formula if the baby was not thriving:

And it's a must for a baby to be breastfed. And sometimes the doctors and the nurses won't discharge you because you don't know how to breastfeed your baby. So they keep you there until you know how to breastfeed. And they also check how you hold your breast when breastfeeding.

And interestingly, there were reports that young mothers fed their infant solids, but would breast-feed in front of staff when they attended the clinic/NGO:

I think my child stopped breast milk after a month because after I gave birth at [name of hospital] she suddenly got ill so she was admitted at [name of hospital]. So I couldn't continue using formula. I had to breastfeed her because I was in front of the doctors and nurse for a month.

Thus, overall, it appears that the young women in this study were aware of the arguments in favor of and against both breast- and formula-feeding, but in practice mixed feeding seemed to occur early after birth of the infant. Moreover, it was significant that no participants mentioned the links between infant feeding and HIV infection, until asked about this, as discussed below.

\section{HIV and feeding}

Participants identified the need to get tested for HIV, and that if the pregnant adolescent was HIV-positive they needed medication. The baby then would also receive medication and consequently not become infected. However, if the infected mother did not take medication, they believed the baby would be infected. Some described that breastmilk could infect the baby, hence the need to formula feed:

Even if a mother is HIV-positive, it is not a must that that child is going to come out positive. Because if they find it early in the pregnancy and they give that child stuff to drink ... just so that the child does not get it.

Normally doctors would suggest that HIV-positive mothers don't breastfeed their babies at all $[\mathrm{mm}]$ because if that baby comes out being HIV-negative, it puts that baby at risk of getting the virus through breastfeeding so they advise the mothers to use formula.

However, there was also the sentiment that if the mother was HIV-positive, the baby would get infected anyway so she may as well breast-feed the infant: 
And so they will not be able to breast-feed ..., or they could since both her and the child have HIV she can breast-feed.

A contradictory position was that if the mother was HIV-positive, she should breastfeed the baby exclusively for six months. Others thought that if the mother was HIV-positive, she should breast- or formula-feed exclusively, and not mix the two. And if she was not HIV-positive, then she could mix breast and formula-feeding:

The HIV-positive mothers have to breast-feed their babies for only six months without giving them water.

All I know is once you like breastfeed your child, you must only breastfeed. And if you do the formula, you must only do the formula. You can't mix the foods.

The positive child has to be breast-fed for six months and must have the breast milk only, while the HIV-negative can have anything both baby formula and the breast milk as well.

It appeared that there was some confusion among participants as to the recommended approach to infant feeding for HIV-positive mothers. Given shifts in feeding guidelines, this confusion is not that surprising. It was noticeable that although participants were aware of the issues around HIV and infant feeding, such issues were not regarded as all that relevant for these young school age women.

\section{School and babies}

There was much debate about mothers staying at home with their infants, or returning to school. Arguments for staying at home included that they needed to bond with the baby, or to take a break after birth and return to school the following year. In addition, there might be no-one else to care for the infant, or not enough money to place the baby in a crèche:

Stay and breast-feed your child properly so that your child is healthy. Then the next year you can take them to crèche when they are almost a year old.

So the parent will tell you not to go back to school: "Stay with your child because I also do not have money to pay for a crèche. I also need to go to work so that we have something to eat in this house."

On the other hand, some thought that young mothers should return to school to complete their education, in order to be able to work to support their children, or to improve their future prospects. In fact, young mothers should be encouraged to return to school, as this was not something to be ashamed of, and this would be an inspiration to others:

... and especially my dad, my dad always told me that I have, not I have to, but he wants me to, to succeed. Even if it's just for me to pass matric. At least that I can go 
somewhere with my matric certificate and that I can provide for my daughter at the end of the day with, with or without my parents help; that I can actually go somewhere and be something for myself and for her.

And those that find the strength [to return to school] and believe in themselves and to better their life for them and their children, I find it amazing.

However, this was not always easy, and breastfeeding at school could be a challenge. Thus, participants advocated the school should be supportive, and provide educare facilities for the baby:

But not everybody will go back to school. Because some people will be so scared of judging them or make remarks ... Most of them wouldn't go back to school because of that.

So you need that support because especially when it comes to school it's really not easy having a baby and being at school.

Related to discussions about whether the adolescent mother should return to school or not, there were perceptions about the role of family, particularly mothers and grandmothers, in supporting young women's feeding practices. On the one hand mothers/grandmothers had been through it before themselves, so knew what to do. They were supportive and could help with feeding and finance the purchase of formula:

And it is older people that are experienced with babies, therefore it's the older people that need to tell you how to feed your child or how to bath them.

I would say that they do influence the decisions mothers make because like that mother is still a child, still at school so they are going to depend on their parents for like money wise, financially wise to look after that baby.

However, mothers and grandmothers were also viewed as wanting to impose their views, often giving conflicting or outdated advice, and therefore were perceived as disapproving and unsupportive:

So my granny was like: "don't eat this and don't eat that"; "do this and do that". And then my mommy would say, "do this and do that", which was opposite to what my grandmother said. And then it made me confused because then I didn't know what to do because I looked up to them because they had kids now already.

Some young mothers reportedly sent their babies to rural areas where they were raised by a mother/grandmother, so the young mother could return to school. This had implications for decisions about breast versus formula-feeding:

There would be children that would fall pregnant. So they would have to return to the [school] hostel. So they would leave the child back home ... So like you're gonna be far from your baby, which means every decision to do with your child is not taken by you but by your mother. 
No I won't breastfeed, I will leave him with my mother ... anyway, so then who is going to continue with the breastfeeding, so I might as well not start.

Interestingly, there was very little mention of the fathers of babies, including their involvement in support of young mothers and their feeding practices. While some fathers were seen as helpful by paying maintenance or buying food, the dominant sentiment was that fathers were not at all supportive, as they would deny that the baby was theirs, abandon the mother once she was pregnant, or show no interest (or support) once the baby was born:

For me I have received the help from my sister and the child's father sometimes. So my sister would help as well as the father of the child.

My friend she got pregnant and she kept the baby and, but the guy denied it

But even now nuh, when she gave birth, her boyfriend left her

This highlights the vulnerability of young mothers, and the importance of family networks. The roles of female family members feature prominently in feeding decision-making of young dependent women. The home context is therefore important to consider in policy and feeding interventions

\section{Discussion}

In the context of infant feeding policy in South Africa that promotes exclusive breastfeeding for 6 months, we explored adolescent women's perspectives on feeding choices of adolescent mothers, acknowledging their perspectives of families, peers and communities.

For informants, breastfeeding, while being desirable economically and preferable for infant care, was only part of infant nutrition. In both communities, mixed feeding commenced often within two weeks of birth. As formula was expensive, porridges and other foods were introduced early. Indeed, early mixed feeding is common in many communities (HunterAdams, Myer, \& Rother, 2016). This raises questions of how best to support safe, practical and affordable infant feeding among adolescent mothers.

Congruent with several studies set in other countries (Bica \& Giugliani, 2014; Bootsri \& Taneepanichskul, 2017; de Oliveira et al., 2014), mothers and grandmothers with experience of childrearing and resources played an important role in the lives of a new baby. In the context of financial dependence, extended family relationships were seen as supportive, providing money for formula, although fathers of babies were generally not seen as playing a role. However, these relationships were not always supportive 
of breastfeeding, and the historical practice of early mixed feeding seemed to play an important role in shaping norms for adolescent mothers. At times adolescent mothers may be fully attuned to health promotion messaging of exclusive breastfeeding, yet the extended family, in which the young mother is a financially dependent member, ultimately plays an important role in defining and shaping feeding choices, and needs to be factored into health promotion programs for infant nutrition.

Participants emphasized that the completion of high school education is in young mothers' and their children's best interest, but felt this would mean either formula-feeding or the introduction of complementary foods for their infants. While school attendance is not emphasized in studies of adolescent breastfeeding (Hackett et al., 2015; Martens, 2001; Nesbitt et al., 2012), in our study, this represented a primary backdrop for feeding decisions. This may be because other options for high school completion are available in North America, whereas in South Africa, these options are relatively hard to access. Globally, options for the completion of school are critically important, and must be considered in country specific education and infant feeding policies.

Nevertheless, return to school meant mixed feeding, as expressing milk was perceived as impossibly time-consuming. In addition, young women were concerned that breastfeeding could negatively affect their appearance.

Participants were very aware of the benefits of breastfeeding, and were supported to establish breastfeeding. There was agreement about the unacceptably high risk of HIV transmission from HIV-infected mothers through mixed feeding, but there was confusion about the risk of HIV transmission in breast milk and the policy of exclusive breastfeeding. This is not surprising given the relatively recent changes in policy (Kindra et al., 2012). Their perspectives on what was advisable for HIV-exposed infants reflected the conflicting pre- and post-2013 Option B+ recommendations of exclusive formula-feeding and breastfeeding for HIV-infected women.

In addition, there were debates about options for HIV-negative mothers. For HIV-uninfected women, who make up most adolescent mothers, more nuanced counseling that addresses both their life-stage and their infants' needs, may be appropriate. Adolescent mothers raised the issue of hiding formula when visiting clinics, which highlights the impact of breastfeeding counseling where there are not open, mutually trusting relationships with nursing staff.

There was no indication that adolescents would be counseled how to navigate their return to school in relation to the care of their child, including feeding, a critical issue for other country contexts. Given the widespread practice of bottle-feeding, clear guidance on the correct preparation of formula, bottle hygiene, and the introduction of complementary foods is 
needed and should be articulated in feeding policy. This guidance must acknowledge and respond to the perception that exclusive breastfeeding is impractical, and acknowledge the cost of formula, the financial dependence of adolescents as well as adolescent mothers' priorities. Adolescent mothers do wish to return to school, and may also be concerned about their physical attractiveness. They may see that exclusive breastfeeding conflicts with these priorities.

\section{Conclusion}

Infant nutrition is critical to the optimal development of children, and sets the stage for life-long development and healthy societies. Infant feeding policy, through promoting exclusive breastfeeding until 6 months of age, with few exceptions, is becoming less confusing for health providers. Policy now promotes exclusive breastfeeding and gradual weaning with the introduction of solids, irrespective of HIV status.

This policy, however, does not speak to the reality of a large group of mothers, adolescent mothers, who need and want to complete schooling. Infant-feeding and educational policies need to address the context of both mothers and children. The well-being of adolescent mothers requires support for the completion of schooling, while supporting practical and healthy infant feeding options.

Infant feeding policies and algorithmic guidelines, in South Africa and elsewhere, need to articulate healthy infant feeding options, and recognize the scenarios of young women. In addition, educational policy, promoting a return to school needs to make provision for resources that support adolescents and their infants. Health promotion interventions to improve infant nutrition should also address knowledge and beliefs of adolescent mothers' mothers and grandmothers.

Research is needed to further explore and expose the disjuncture between infant feeding and educational policies. This should include engagement with policy makers in the health and education sectors, as well as with front line health and education staff who manage adolescent mothers and implement policy. Such research could surface innovations and opportunities that would serve the interests of both the adolescent girl and her infant, and would feed into health and educational policy that contains options and detail not present in current policy.

Following the 'first 1000 days' approach, health and education policy need to articulate resources that can be leveraged, promoting the psychosocial health of the mother, that includes completing schooling, while also promoting safe, healthy nutrition for the infant, so that both mother and infant can thrive. 


\section{Disclosure statement}

The authors declare that none have any financial interest or benefit that has arisen or will arise from any application of this research.

\section{Funding}

This work was supported by the University of Cape Town Research Office, by Urban Food Systems Governance for NCD Prevention in South Africa, Kenya and Namibia (Nourishing Spaces) IDRC Project \# 108458 and by the South African Research Chairs Initiative (Chair in 'Health and Wealth') of the Department of Science and Technology and National Research Foundation of South Africa (Any opinion, finding and conclusion or recommendation expressed in this article is that of the authors and the NRF does not accept any liability in this regard.)

\section{ORCID}

Virginia Zweigenthal (D) http://orcid.org/0000-0003-3914-2156

\section{References}

Bearinger, L. H., Sieving, R. E., Ferguson, J., \& Sharma, V. (2007). Global perspectives on the sexual and reproductive health of adolescents: Patterns, prevention, and potential. The Lancet, 369(9568), 1220-1231.

Bhutta, Z. A., Das, J. K., Rizvi, A., Gaffey, M. F., Walker, N., Horton, S., Black, R. E. (2013). Evidence-based interventions for improvement of maternal and child nutrition: What can be done and at what cost? The Lancet, 382(9890), 452-477. doi:10.1016/ S0140-6736(13)60996-4

Bica, O. C., \& Giugliani, E. R. J. (2014). Influence of counseling sessions on the prevalence of breastfeeding in the first year of life: A randomized clinical trial with adolescent mothers and grandmothers. Birth (Berkeley, Calif.), 41(1), 39-45.

Bland, R. M., Rollins, N. C., Coutsoudis, A., \& Coovadia, H. M. (2002). Breastfeeding practices in an area of high HIV prevalence in rural South Africa. Acta Paediatrica, 91(6), 704-711. doi:10.1080/080352502760069151

Bootsri, W., \& Taneepanichskul, S. (2017). Effectiveness of experiential learning with empowerment strategies and social support from grandmothers on breastfeeding among Thai adolescent mothers. International Breastfeeding Journal, 12(1), 37.

Boyatzis, R. E. (1998). Transforming qualitative information: Thematic analysis and code development. Thousand Oaks: Sage.

Coovadia, H. M., Rollins, N. C., Bland, R. M., Little, K., Coutsoudis, A., Bennish, M. L., \& Newell, M.-L. (2007). Mother-to-child transmission of HIV-1 infection during exclusive breastfeeding in the first 6 months of life: An intervention cohort study. The Lancet, 369(9567), 1107-1116. doi:10.1016/S0140-6736(07)60283-9

de Oliveira, L. D., Giugliani, E. R. J., do Espírito Santo, L. C., \& Nunes, L. M. (2014). Counselling sessions increased duration of exclusive breastfeeding: A randomized clinical trial with adolescent mothers and grandmothers. Nutrition Journal, 13(1), 73. 
Department of Health. (2012). Regulations relating to foodstuffs for infants and young children. Pretoria: Government Gazette. Retrieved from http://blogs.sun.ac.za/iplaw/files/ 2013/12/ZAF-2012-Regulations-relating-to-foodstuffs-for-infants-and-young-children-R.No.-991-of-2012_0.pdf

Department of Health. (2013). The South African antiretrovital treatment guidelines. PMTCT Guidelines: Revised March 2013. Pretoria. Retrieved from https://www.westerncape.gov.za/assets/ndoh_pmtct_guidelines.pdf

Doherty, T., Chopra, M., Nkonki, L., Jackson, D., \& Greiner, T. (2006). Effect of the HIV epidemic on infant feeding in South Africa: "When they see me coming with the tins they laugh at me." Bulletin of the World Health Organization, 84(2), 90-96. doi:10.2471/ BLT.04.019448

Doherty, T., Sanders, D., Jackson, D., Swanevelder, S., Lombard, C., Zembe, W., Tylleskär, T. (2012). Early cessation of breastfeeding amongst women in South Africa: An area needing urgent attention to improve child health. BMC Pediatrics, 12, 105. doi:10.1186/ 1471-2431-12-105

Dykes, F., Moran, V. H., Burt, S., \& Edwards, J. (2003). Adolescent mothers and breastfeeding: Experiences and support needs-an exploratory study. Journal of Human Lactation, 19(4), 391-401.

Grant, M. J., \& Hallman, K. K. (2008). Pregnancy-related school dropout and prior school performance in KwaZulu-Natal, South Africa. Studies in Family Planning, 39(4), 369-382.

Hackett, K. M., Mukta, U. S., Jalal, C. S., \& Sellen, D. W. (2015). Knowledge, attitudes and perceptions on infant and young child nutrition and feeding among adolescent girls and young mothers in rural Bangladesh. Maternal \& Child Nutrition, 11(2), 173-189.

Hannon, P. R., Willis, S. K., Bishop-Townsend, V., Martinez, I. M., \& Scrimshaw, S. C. (2000). African-American and Latina adolescent mothers' infant feeding decisions and breastfeeding practices: A qualitative study. Journal of Adolescent Health, 26(6), 399-407.

Hunter-Adams, J., Myer, L., \& Rother, H.-A. (2016). Perceptions related to breastfeeding and the early introduction of complementary foods amongst migrants in Cape Town, South Africa. International Breastfeeding Journal, 11(1), 29.

Jewkes, R., Morrell, R., \& Christofides, N. (2009). Empowering teenagers to prevent pregnancy: Lessons from South Africa. Culture, Health \& Sexuality, 11(7), 675-688.

Kaufman, C. E., Wet, T., \& Stadler, J. (2001). Adolescent pregnancy and parenthood in South Africa. Studies in Family Planning, 32(2), 147-160.

Kindra, G., Coutsoudis, A., Esposito, F., \& Esterhuizen, T. (2012). Breastfeeding in HIV exposed infants significantly improves child health: A prospective study. Maternal and Child Health Journal, doi:10.1007/s10995-011-0795-8

Martens, P. J. (2001). The effect of breastfeeding education on adolescent beliefs and attitudes: A randomized school intervention in the Canadian Ojibwa community of Sagkeeng. Journal of Human Lactation, 17(3), 245-255.

Meglio, G. D., McDermott, M. P., \& Klein, J. D. (2010). A randomized controlled trial of telephone peer support's influence on breastfeeding duration in adolescent mothers. Breastfeeding Medicine, 5(1), 41-47.

Nesbitt, S. A., Campbell, K. A., Jack, S. M., Robinson, H., Piehl, K., \& Bogdan, J. C. (2012). Canadian adolescent mothers' perceptions of influences on breastfeeding decisions: A qualitative descriptive study. BMC Pregnancy and Childbirth, 12(1), 149.

Nor, B., Ahlberg, B. M., Doherty, T., Zembe, Y., Jackson, D., \& Ekstr, M. E. C. (2012). Mother's perceptions and experiences of infant feeding within a community-based peer 
counselling intervention in South Africa. Maternal \& Child Nutrition, 8(4), 448-458. doi:10.1111/j.1740-8709.2011.00332.x

Panday, S., Makiwane, M., Ranchod, C., \& Letsoalo, T. (2009). Teenage pregnancy in South Africa - with a specific focus on school-going learners. Retrieved from https://www.education.gov.za/LinkClick.aspx?fileticket=uIqj\%2BsyyccM\%3D

Shah, S., Rollins, N. C., Bland, R., \& Group, H. (2005). Breastfeeding knowledge among health workers in rural South Africa. Journal of Tropical Pediatrics. 51(1), 33-38. doi:10. 1093/tropej/fmh071

Sibeko, L., Dhansay, M. A., Charlton, K. E., Johns, T., Gray-Donald, K., Charlton, K. E., Gray-Donald, K. (2005). Beliefs, attitudes and practices of breastfeeding mothers from a periurban community in South Africa. Journal of Human Lactation, 21(1), 31. doi:10. $1177 / 0890334404272388$

Statistics South Africa. (2012). Census 2011: Statistical release. Pretoria: Statistics South Africa.

Timæus, I. M., \& Moultrie, T. A. (2015). Teenage childbearing and educational attainment in South Africa. Studies in Family Planning, 46(2), 143-160.

Wambach, K. A., \& Cohen, S. M. (2009). Breastfeeding experiences of urban adolescent mothers. Journal of Pediatric Nursing, 24(4), 244-254.

Woods, N. K., Chesser, A. K., \& Wipperman, J. (2013). Describing adolescent breastfeeding environments through focus groups in an urban community. Journal of Primary Care \& Community Health, 4(4), 307-310. 